\title{
Comparative genomic analysis of Vibrios yields insights into genes associated with virulence towards C. gigas larvae
}

\author{
Hanna Kehlet-Delgado ${ }^{1 *} \mathbb{D}$, Claudia C. Häse ${ }^{2}$ and Ryan S. Mueller ${ }^{1}$
}

\begin{abstract}
Background: Vibriosis has been implicated in major losses of larvae at shellfish hatcheries. However, the species of Vibrio responsible for disease in aquaculture settings and their associated virulence genes are often variable or undefined. Knowledge of the specific nature of these factors is essential to developing a better understanding of the environmental and biological conditions that lead to larvae mortality events in hatcheries. We tested the virulence of 51 Vibrio strains towards Pacific Oyster (Crassostreae gigas) larvae and sequenced draft genomes of 42 hatchery-associated vibrios to determine groups of orthologous genes associated with virulence and to determine the phylogenetic relationships among pathogens and non-pathogens of C. gigas larvae.

Results: $V$. coralliilyticus strains were the most prevalent pathogenic isolates. A phylogenetic logistic regression model identified over 500 protein-coding genes correlated with pathogenicity. Many of these genes had straightforward links to disease mechanisms, including predicted hemolysins, proteases, and multiple Type 3 Secretion System genes, while others appear to have possible indirect roles in pathogenesis and may be more important for general survival in the host environment. Multiple metabolism and nutrient acquisition genes were also identified to correlate with pathogenicity, highlighting specific features that may enable pathogen survival within C. gigas larvae.
\end{abstract}

Conclusions: These findings have important implications on the range of pathogenic Vibrio spp. found in oysterrearing environments and the genetic determinants of virulence in these populations.

Keywords: Vibrio, Aquaculture, Comparative genomics, Oyster larvae, Vibrio coralliilyticus, Vibriosis, Crassostrea gigas, Prokaryotic genomics

\section{Background}

The Vibrio genus represents a group of microorganisms ubiquitous in temperate marine, freshwater, and estuarine environments [1-3]. Members of this genus are known to have roles as commensal or pathogenic members of marine animal microbiomes [4, 5], or as free-living members of the environment $[6,7]$. Incidences of diseases attributed to Vibrio bacteria are

* Correspondence: kehletdelgado@gmail.com

'Department of Microbiology, Oregon State University, Corvallis, Oregon 97331, USA

Full list of author information is available at the end of the article broadly referred to as "vibriosis", with the identities of the etiological agents and their pathogenic mechanisms varying between hosts. In aquaculture settings, vibriosis outbreaks can lead to large economic and productivity impacts [8]. Commercial shellfish hatcheries are impacted by disease outbreaks attributed to vibrios, which can result in large mass mortalities of larvae [9-12].

Genomic sequencing of marine pathogens has aided our understanding of the genetic mechanisms of virulence in some of these systems. Within some species of Vibrio, there are well-defined mechanisms for virulence. For instance, within the Splendidus clade of Vibrios, numerous

(c) The Author(s). 2020 Open Access This article is licensed under a Creative Commons Attribution 4.0 International License, which permits use, sharing, adaptation, distribution and reproduction in any medium or format, as long as you give appropriate credit to the original author(s) and the source, provide a link to the Creative Commons licence, and indicate if changes were made. The images or other third party material in this article are included in the article's Creative Commons licence, unless indicated otherwise in a credit line to the material. If material is not included in the article's Creative Commons licence and your intended use is not permitted by statutory regulation or exceeds the permitted use, you will need to obtain permission directly from the copyright holder. To view a copy of this licence, visit http://creativecommons.org/licenses/by/4.0/ The Creative Commons Public Domain Dedication waiver (http://creativecommons.org/publicdomain/zero/1.0/) applies to the data made available in this article, unless otherwise stated in a credit line to the data. 
virulence factors, including an exported protein of unknown function, gene $r 5.7$ [13, 14], species-specific Type 6 Secretion System effectors [15], and the MultifunctionalAutoprocessing Repeats-in-Toxin (MARTX) cluster [14], have been shown to affect Pacific Oyster (Crassostrea gigas) adults and juveniles. The importance of a zinc metalloprotease has also been reported in several Vibrio oyster pathogens, including $V$. tasmaniensis [16], $V$. aestuarianus [17], and V. coralliilyticus [18]. V. coralliilyticus, long established to be a coral pathogen [19-21], has also been implicated in significant mortality events of larvae at shellfish hatcheries [11,22-25] and of C. gigas larvae in laboratory experiments $[18,24-26]$. The outer membrane protein OmpU and the ToxR transcriptional regulator have also been implicated in virulence of $V$. coralliilyticus towards C. gigas larvae [27]. However, it is unclear if there are other genetic mechanisms contributing to $V$. coralliilyticus oyster larvae pathogenesis and what their conservation is across the Vibrio genus and whether other Vibrio strains found within aquaculture settings interact with shellfish and what their impacts on oyster health may be. Genome comparisons of vibrios with varying virulence phenotypes are an imperative step in identifying the genes associated with pathogenesis.

In this study, the genomes of 42 Vibrio isolates were sequenced and compared to identify and characterize conserved genomic features contributing to mortalities of $C$. gigas larvae. These isolates, along with nine previously sequenced strains, were tested for pathogenicity towards C. gigas larvae. Most isolates exhibiting pathogenic phenotype were identified as belonging to the $V$. coralliilyticus species group, emphasizing the identity of this species as a notable pathogen. By contrasting phenotypes with genotype data, we present an in-depth comparative analysis into the genomic repertoire of pathogenic and non-pathogenic vibrios found in aquaculture environments. Additionally, we introduce insights into the genomic content of $V$. coralliilyticus strains, and put forward evidence for what genes may be responsible for $V$. coralliilyticus vibriosis of $C$. gigas larvae.

\section{Results}

\section{Pathogenicity of Vibrio isolates against C. gigas larvae}

Survival of larvae with non-control bacterial strains $(n=49)$ ranged from 0 to $100 \%$, with an average mortality across all trials of $35.7 \%$ (std. dev. 40.3\%) and median of $13.0 \%$ (Fig. 1). Results approximate a bimodal distribution, with individual isolates displaying either high pathogenicity or having little effect on oyster survival. Members of the high-pathogenicity group consistently caused larvae mortalities between 51 and $100 \%$ and primarily included isolates identified as $V$. coralliilyticus strains. Only two isolates not classified as $V$. coralliilyticus resulted in high mortalities: strain Vibrio sp. strain RE88 $(99 \% \pm 3 \%)$ and $V$. mediterranei strain $71,105(79 \% \pm 0.10 \%)$. The lowpathogenicity group was comprised of a more diverse set of Vibrio species. Thirty-nine isolates tested positive for hemolytic activity on 5\% horse blood agar and 44 isolates tested positive for proteolytic activity on $2 \%$ skim milk agar (Additional file 1: Table S1).

\section{Genome features, phylogenetics, and comparative genomics}

To better understand the genomic potential of hatchery-associated vibrios and identify traits that are associated with virulence, we conducted whole-genome shotgun sequencing, assembly, and annotation of the 42 isolates (Table 1). Isolates spanned a wide range of species within the Vibrio genus. Ten newly sequenced genomes were designated as $V$. coralliilyticus based on ANI relationships (Additional file 2: Fig. S1). Eight strains did not have $>95 \%$ ANI with any reference type strains, preventing species-level classification. One of these, Vibrio sp. RE88, was closely related to the $V$. coralliilyticus ATCC BAA $-450^{\mathrm{T}}$ at $94 \%$ ANI, but under the species-threshold of $95-96 \%$ ANI. Three strains, T3Y01, 070316B, and $99 \mathrm{~K}-1$, all had over 98\% ANI among pairs, but were not related to any other reference genome in the database tested, indicating that these are possibly a novel species group. A universal gene phylogeny supports the taxonomic assignments based on ANI relationships (Fig. 2), and clusters most of the isolates into two main clades: the Coralliilyticus clade and the Splendidus clade. These data were congruent with a phylogenetic tree built from concatenated sequences of the computationally-determined core genome of 154 Vibrionaceae genomes (Additional file 3: Fig. S2), scoring a Kuhner-Felsenstein (KF) [31] distance of 0.209 .

The core, flex, and pan-genomes of isolate genomes were classified to determine the functional composition of the conserved and unique genes. OrthoMCL [32] clustering defined a total of 1693 core genes, 11,327 flexible genes, and 23,933 genes in the pan genome of sequenced strains. Core and pan-genome gene accumulation plots were created (Additional file 4: Fig. S3), and the curve of the pan-genome plot and the Heaps law model (alpha $=0.47$ ) indicated an open-pan genome amongst these isolates.

The observed distribution of functional categories of the genes significantly correlated with the results of larval pathogenicity assays was significantly different than that of the genes in the core genome (chi-square $=$ 3979.2, $\mathrm{df}=19, \quad p<0.001)$. The functional categories "Carbohydrate transport and metabolism", "Transcription", "Secondary metabolites biosynthesis, transport and 


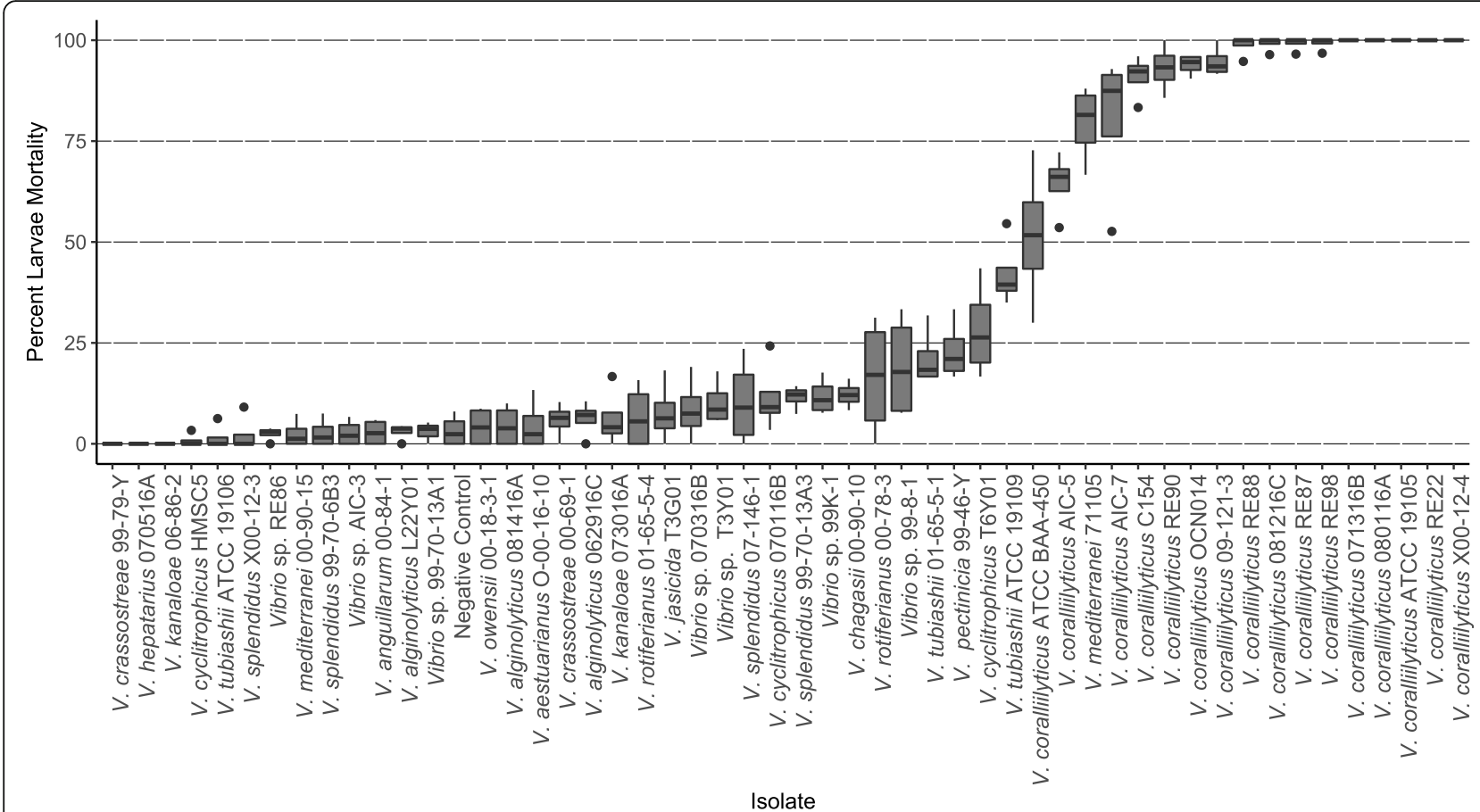

Fig. 1 Mortality of C. gigas larvae in pathogenicity experiments tested against 51 Vibrio strains. Boxes represent the median value, the 25 th percentile, and the 75th percentile. Outliers represent values greater than 1.5 times outside these percentiles. Percent mortalities within nobacterial controls averaged $6.8 \%$ (std. dev. 0.077)

catabolism", "Function unknown", and "Signal transduction mechanisms" were significantly enriched in the flexible genome relative to the core genome $(p<0.05)$. The category of genes without any significant hits to the GAMMAPROTNOG database was also significantly enriched in the flex genome $(p<0.05)$.

\section{Genes associated with C. gigas larvae pathogenicity}

To identify genes associated with $C$. gigas larval mortalities we implemented a phylogenetic logistic regression model using gene presence/absence and pathogenicity assay data for each isolate. A total of 508 genes were identified to have a significant negative correlation with larvae survival $(p<0.005)$, while only 19 genes had a significant positive correlation with survival (Fig. 2 and Additional file 5: Table S2). Since most of the pathogenic isolates were putatively assigned as $V$. coralliilyticus species, we used coding sequences from the complete genome sequence of $V$. coralliilyticus strain RE22 (Accession: GCA_003391375) as a reference for gene annotations, and to compare the synteny of contigs from isolate genome assemblies. Three eggNOG functional categories were significantly enriched in the group of genes correlated with high mortality/low survival phenotypes compared to the functional composition of core genome from all strains (Supporting Fig. 3): "Carbohydrate transport and metabolism" (G; $p=0.0365)$; "Secondary metabolite biosynthesis, transport and catabolism" (Q; $p=5.27 \mathrm{E}-06)$; "Function unknown" (S; $p=4.11 \mathrm{E}-11)$; and a fourth category containing genes that did not have significant hits to the database $(p=0)$. Metabolic genes were a dominant component of these functional categories and included chitinase A precursors, a bile acid symporter, a pectate lyase, and multiple sugar degradation enzymes (Additional file 6: Table S3).

Additional genes found to be negatively correlated with larvae survival included those with annotations putatively involved with host virulence. A group of $r e b$ genes were significant $(C=3.48, p=0.0005)$ (Table 2$)$, with most being exclusive to and conserved within the $V$. coralliilyticus group of isolates. The putative reb genes were located within a larger putative genomic island of the RE22 complete genome $(\sim 30 \mathrm{~KB})$ that encoded multiple genes found to be significant with larvae pathogenicity outcomes, including an endolysin (AXN33720.1), a methyltransferase (AXN33721.1), a putative methyl-accepting chemotaxis protein (AXN3372 4.1), and multiple hypothetical proteins.

Genes coding for a Type 1 Secretion System (T1SS) (AXN34790.1, AXN34851.1, and AXN34791.1) were significant based on the phylogenetic logistic regression analysis $(p<0.0005)$, although this region, located in $V$. coralliilyticus strain RE22 on the p337 plasmid, was not conserved in all isolates of this species. Additional genetic features with potential virulence functions included 
Table 1 Bacterial strains and genomes used in this study

\begin{tabular}{|c|c|c|c|c|c|}
\hline Species & Strain & Year & Location & Reference & Accession ID \\
\hline V. alginolyticus & 062916C & 2016 & Oregon & This study* & VTYI00000000 \\
\hline V. alginolyticus & $081416 \mathrm{~A}$ & 2016 & Oregon & This study* & VTYF00000000 \\
\hline V. alginolyticus & L22Y01 & 2015 & Washington & This study* & VTYJ00000000 \\
\hline V. anguillarum & $00-84-1$ & 2000 & Washington & This study* & VTYO00000000 \\
\hline V. chagasii & 00-90-10 & 2000 & Hawaii & This study* & VTXW00000000 \\
\hline V. coralliilyticus & 071316B & 2016 & Oregon & This study* & VTYG00000000 \\
\hline V. coralliilyticus & 080116A & 2016 & Oregon & [28] & GCA_002286405 \\
\hline V. coralliilyticus & $081216 C$ & 2016 & Oregon & This study* & VTYE00000000 \\
\hline V. coralliilyticus & 09-121-3 & Unknown & Unknown & This study* & VTXP00000000 \\
\hline V. coralliilyticus & 19,105 & 1965 & Conneticut & {$[22]^{*}$} & VTXA00000000 \\
\hline V. coralliilyticus & AIC-5 & 2015 & New Jersey & This study* & VTXB00000000 \\
\hline V. coralliilyticus & AIC-7 & 2015 & New Jersey & [28] & GCA_002287625 \\
\hline V. coralliilyticus & BAA-450 & 1999 & Indian Ocean & [20] & ACZN00000000 \\
\hline V. coralliilyticus & C154 & 2017 & Washington & This study* & VTYL00000000 \\
\hline V. coralliilyticus & OCN014 & 2010 & Palmyra Atoll & [29] & GCA_000763535 \\
\hline V. coralliilyticus & RE22 & 2000 & Oregon & [23] & GCA_003391375.1 \\
\hline V. coralliilyticus & RE87 & 1999 & Hawaii & [11] & GCA_002286655 \\
\hline V. coralliilyticus & RE88 & 2000 & Hawaii & [11] & VTYQ00000000 \\
\hline V. coralliilyticus & RE90 & 2000 & Hawaii & [11] & VTYR00000000 \\
\hline V. coralliilyticus & RE98 & 2000 & Oregon & [23] & GCA_000772065.1 \\
\hline V. coralliilyticus & $x 00-12-4$ & 2000 & Oregon & {$[23]^{*}$} & VTYS00000000 \\
\hline V. crassostreae & $00-69-1$ & 2000 & Washington & This study* & VTXY00000000 \\
\hline V. crassostreae & 99-79-Y & 1999 & Washington & {$[23]^{*}$} & VTXZ00000000 \\
\hline V. cyclitrophicus & HMSC5 & 2000 & Oregon & [27] & VTYP00000000 \\
\hline V. cyclitrophicus & T6Y01 & 2015 & Washington & This study* & VTYK00000000 \\
\hline V. cyclitrophicus & 070116B & 2016 & Oregon & This study* & VTYB00000000 \\
\hline V. hepatarius & 070516A & 2016 & Oregon & This study* & VTYD00000000 \\
\hline V. jasicida & T3G01 & 2015 & Washington & This study* & VTXQ00000000 \\
\hline V. kanaloae & $06-86-2$ & 2006 & Oregon & [30] & VTXR00000000 \\
\hline V. kanaloae & 073016A & 2016 & Oregon & This study* & VTXS00000000 \\
\hline V. mediterranei & 00-90-15 & 2000 & Hawaii & This study* & VTXV00000000 \\
\hline V. mediterranei & 71105 & Unknown & Florida & This study* & VTXU00000000 \\
\hline V. owensii & $00-18-3-1$ & 2000 & Hawaii & This study* & VTXX00000000 \\
\hline V. rotiferianus & $00-78-3$ & 2000 & Hawaii & This study* & VTYN00000000 \\
\hline V. rotiferianus & $01-65-5-4$ & 2000 & Hawaii & This study* & VTXT00000000 \\
\hline Vibrio sp. & 070316B & 2016 & Oregon & This study* & VTYC00000000 \\
\hline V. pectenicida & $99-46-Y$ & 2000 & Washington & This study* & VTXC00000000 \\
\hline Vibrio sp. & $99-70-13 \mathrm{~A} 1$ & 2000 & Oregon & This study* & VTXD00000000 \\
\hline Vibrio sp. & $99-8-1$ & 1999 & Washington & This study* & VTXE00000000 \\
\hline Vibrio sp. & $99 \mathrm{~K}-1$ & 2000 & Hawaii & This study* & VTXF00000000 \\
\hline Vibrio sp. & $\mathrm{AlC}-3$ & 2016 & New Jersey & This study* & VTXG00000000 \\
\hline V. aestuarianus & O-00-16-10 & Unknown & Washington & This study* & VTXH00000000 \\
\hline Vibrio sp. & RE86 & 2000 & Hawaii & {$[11]^{*}$} & VTXI00000000 \\
\hline V. splendidus & T3Y01 & 2015 & Washington & This study* & VTXJ00000000 \\
\hline
\end{tabular}


Table 1 Bacterial strains and genomes used in this study (Continued)

\begin{tabular}{llllll}
\hline Species & Strain & Year & Location & Reference & Accession ID \\
\hline V. splendidus & 07-146-1 & 2000 & California & This study* & VTXK00000000 \\
V. splendidus & $99-70-13$ A3 & 2000 & Oregon & This study* & VTXL00000000 \\
V. splendidus & $99-70-6 B 3$ & 2000 & Oregon & This study* & VTXM000000000 \\
V. splendidus & X00-12-3 & 2000 & Oregon & This study* & VTXN00000000 \\
V. tubiashii & $01-65-5-1$ & 2000 & Hawaii & This study* & VTXO00000000 \\
V. tubiashii & 19106 & 1965 & Connecticut & [22] & GCA_000259295 \\
V. tubiashii & 19109 & 1965 & Connecticut & [22] & GCA_000772105 \\
\hline
\end{tabular}

*Genome sequence and assembled as a part of this work

a coding sequence with a haem-degrading domain (AXN33843.1; $\mathrm{C}=3.48, p=0.0005$ ), a gene with poreforming and peptidase domains (AXN34842.1), regulatory proteins and hypothetical proteins $(\mathrm{C}>2.8, p<$ $0.005)$, a gene coding for a necrosis-inducing protein NPP1 (AXN30583.1; C = 3.48, $p=0.0005$ ), and a gene with a domain similar to the cysteine proteinase peptidase_C58 superfamily (AXN33813.1; C $=5.21, p=0.0005)$.
Within the large chromosome of the RE22 genome, a number of syntenic loci whose presences were significantly negatively correlated with larvae survival had annotations for a functional Type 3 Secretion System (T3SS; Fig. 3). The genomic region containing these genes corresponds to the pathogenicity island CPI-1 [33]. In addition to encoding a T3SS and effectors, this region includes genes for multiple

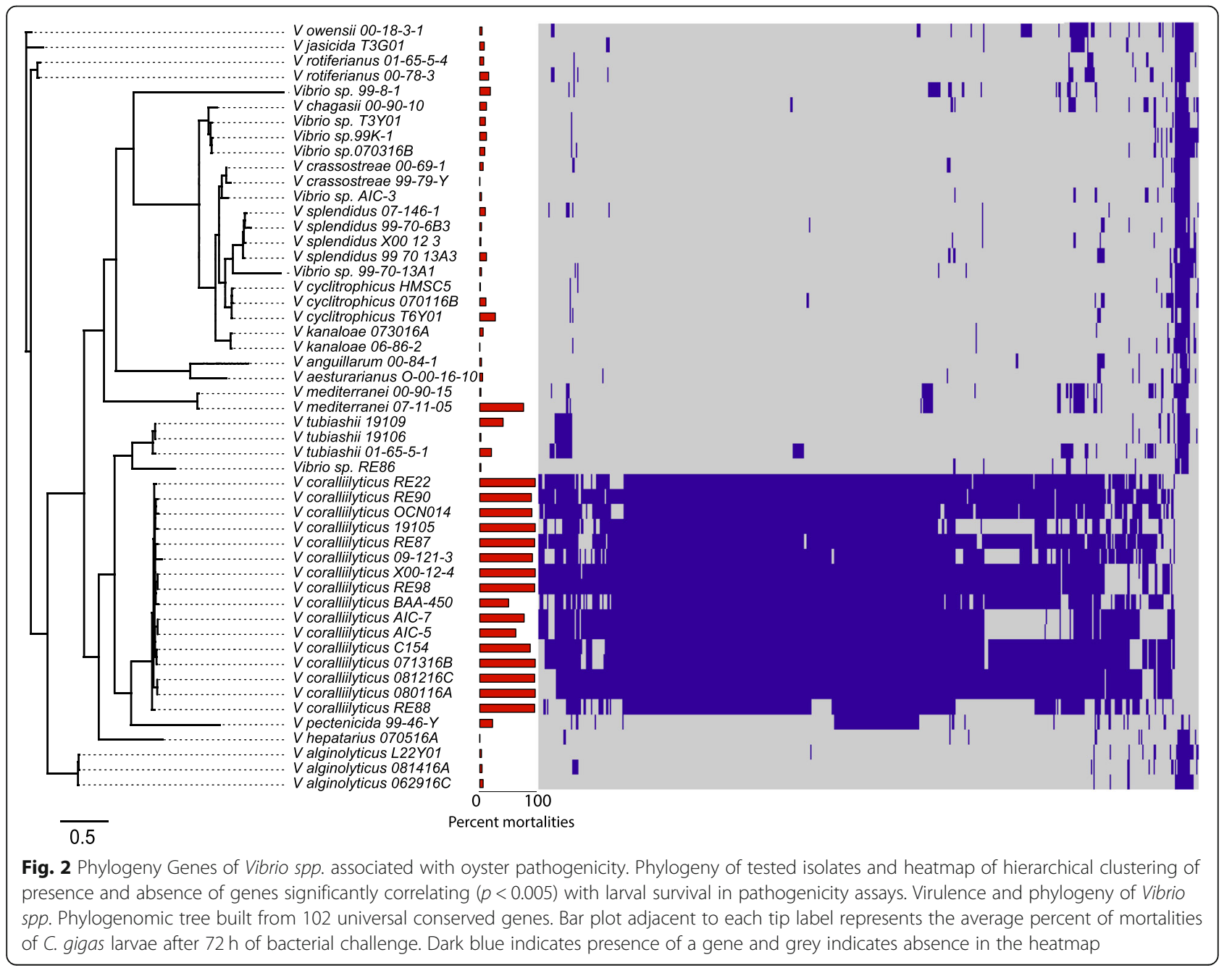




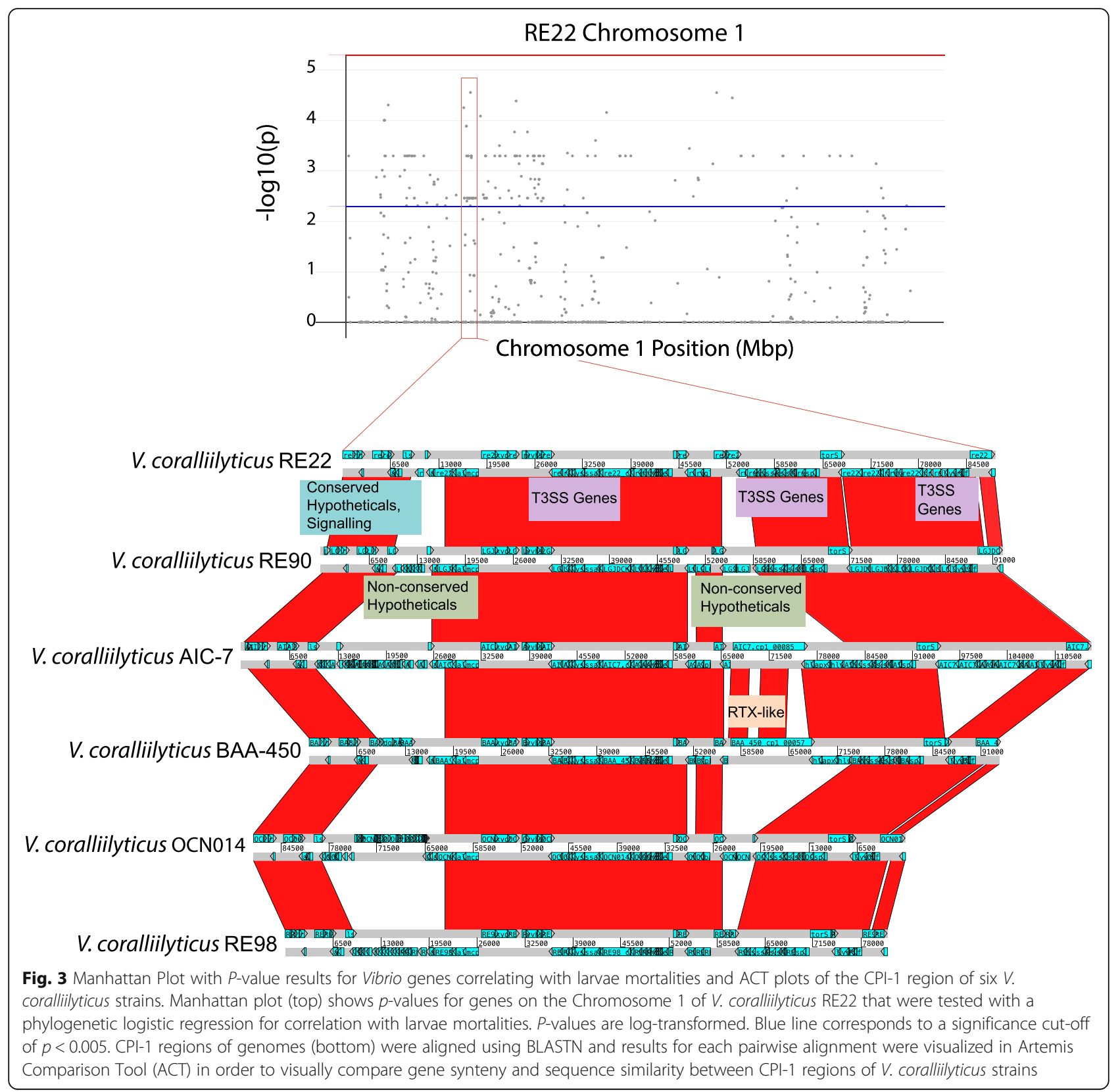

transcriptional regulators, a rhombotail lipoprotein, an anthranilate synthase component II, the hemolysin locus $v \operatorname{ch} A B$, a glutathione-dependent formaldehydeactivating enzyme (GFA)-related enzyme, and hypothetical proteins (Additional file 7: Fig. S4). This genomic island is conserved in all $V$. coralliilyticus genomes examined in this study, as well as the closely-related Vibrio sp. strain RE88. It is not encoded in $V$. mediterranei strain 71,105 , though, which was found to cause high mortalities in oyster larvae. The CPI-1 island was not fully present in strains causing low mortality rates. $V$. pectenicida strain 99-46-Y, which causes low levels of mortality, encodes a partial CPI-1-like island, which encodes the T3SS structural genes and putative effectors (Additional file 8: Fig. S5).

A comparison of the CPI-1 region of six $V$. coralliilyticus genomes revealed that the general architecture of this region ranged from 81 to $112 \mathrm{~kb}$ in length and consisted of several regions of conserved gene content interspaced with more variable regions (Fig. 3), including a locus containing an RTX-like coding sequence and T1SS machinery. Phylogenetic analysis of the $s c t V$ gene, which encodes a conserved protein of the T3SS, indicated that this gene is more similar to those of species of Yersinia, Salmonella, Escherichia, Edwardsiella and Shewanella, 
Table 2 Features of the putative Reb-coding region of Vibrio coralliilyticus strain RE22

\begin{tabular}{|c|c|c|c|c|c|}
\hline $\begin{array}{l}\text { V. coralliilyticus RE } 22 \text { coding } \\
\text { sequence accession }\end{array}$ & $\begin{array}{l}\text { Amino Acid } \\
\text { Length }\end{array}$ & $\begin{array}{l}\text { Phylogenetic Logistic } \\
\text { Regression } p \text {-value }\end{array}$ & Putative function & Domain $\mathrm{Hit}^{\mathrm{b}}$ & $\begin{array}{l}\text { Domain } \\
\text { Accession }\end{array}$ \\
\hline AXN33720.1 & 296 & $5.73 \mathrm{E}-04$ & Muraidase & Muraidase & pfam11860 \\
\hline AXN33721.1 & 261 & $5.02 \mathrm{E}-04$ & $\begin{array}{l}\text { SAM-dependent } \\
\text { methyltransferase }\end{array}$ & Methyltransf 23 & pfam13489 \\
\hline AXN33722.1 & 518 & $5.02 \mathrm{E}-04$ & $\begin{array}{l}\text { Cystine-binding periplasmic } \\
\text { protein }\end{array}$ & $\begin{array}{l}\text { Periplasmic Binding } \\
\text { Protein Type } 2\end{array}$ & $\mathrm{cl} 21456$ \\
\hline AXN33723.1 & 207 & $5.02 \mathrm{E}-04$ & HisM & HisM & cl34036 \\
\hline AXN33724.1 & 692 & $5.02 \mathrm{E}-04$ & MCP protein & PDC2 MCP like & cd12912 \\
\hline AXN33725.1 & 258 & $5.02 \mathrm{E}-04$ & $\begin{array}{l}\text { Intermediate filament tail } \\
\text { domain protein }\end{array}$ & Lamin Tail Domains & pfam00932 \\
\hline AXN33726.1 & 320 & $5.02 \mathrm{E}-04$ & hypothetical protein & ND & ND \\
\hline AXN33727.1 & 140 & $5.02 \mathrm{E}-04$ & hypothetical protein & ND & ND \\
\hline AXN33728.1 & 99 & $5.02 \mathrm{E}-04$ & hypothetical protein & ND & ND \\
\hline AXN33729.1 & 261 & $5.02 \mathrm{E}-04$ & hypothetical protein & ND & ND \\
\hline AXN33730.1 & 235 & $5.02 \mathrm{E}-04$ & hypothetical protein & ND & ND \\
\hline AXN33731.1 & 283 & $5.02 \mathrm{E}-04$ & hypothetical protein & ND & ND \\
\hline AXN33732.1 & 197 & $5.02 \mathrm{E}-04$ & hypothetical protein & ND & ND \\
\hline AXN33733.1 & 304 & 0.9998 & short chain dehydrogenase & sepiapterin reductase & TIGR01500 \\
\hline AXN33734.1 & 658 & 0.99998 & hypothetical protein & ND & ND \\
\hline AXN33735.1 & 632 & 1 & phospholipase & PLDC SF & cl15239 \\
\hline AXN33736.1 & 420 & 1 & Tat pathway signal protein & ND & ND \\
\hline AXN34531.1 & 184 & 1 & hypothetical protein & ND & ND \\
\hline AXN33737.1 & 297 & ND & hypothetical protein & ND & ND \\
\hline AXN33738.1 & 297 & ND & hypothetical protein & ND & ND \\
\hline AXN33739.1 & 1187 & ND & hypothetical protein & ND & ND \\
\hline AXN33740.1 & 88 & $5.02 \mathrm{E}-04$ & hypothetical protein & ND & ND \\
\hline AXN33741.1 & 63 & $5.02 \mathrm{E}-04$ & Reb-like protein & Reb & cl13232 \\
\hline AXN33742.1 & 90 & $5.02 \mathrm{E}-04$ & Reb & Reb & pfam11747 \\
\hline AXN33743.1 & 87 & $5.02 \mathrm{E}-04$ & hypothetical protein & conj TIGR03752 & cl26990 \\
\hline AXN33744.1 & 142 & $5.02 \mathrm{E}-04$ & Reb-like protein & Reb & cl13232 \\
\hline AXN33745.1 & 97 & $3.45 \mathrm{E}-03$ & hypothetical protein & ND & ND \\
\hline AXN33746.1 & 87 & $5.02 \mathrm{E}-04$ & Reb & Reb & pfam11747 \\
\hline AXN33747.1 & 86 & $5.02 \mathrm{E}-04$ & Reb & Reb & pfam11747 \\
\hline AXN33748.1 & 88 & $5.02 \mathrm{E}-04$ & Reb & Reb & pfam11747 \\
\hline AXN33749.1 & 66 & $5.02 \mathrm{E}-04$ & Reb-like protein & Reb & cl13232 \\
\hline AXN33750.1 & 403 & $5.02 \mathrm{E}-04$ & AraC transcriptional reg. & AtoC & cl34427 \\
\hline
\end{tabular}

ND No domain hits were found for that sequence.

Bold values indicate significant phylogenetic logistic regression results $(p<0.005)$.

a Accession number GCA_003391375.1

b Top domain identified using the Conserved Domain Database

and separate from the sct $V$ genes of $V$. parahaemolyticus, $V$. cholerae, $V$. alginolyticus, and $V$. harveyi (Additional file 9: Fig. S6).

\section{Discussion}

Here, we examined the ability of Vibrio isolates to cause mortality of $C$. gigas larvae under controlled experiments. Many of these isolates were collected from hatcheries where C. gigas larvae are produced. Comparative analysis of the genomes of these 51 isolates identified genes specifically associated with a pathogenic lifestyle from the large pan-genome. We found a strong phylogenetic signal among the strains that caused high mortalities; 15 out of 17 strains tested resulting in $50 \%$ 
or higher mortality rates were putatively identified as $V$. coralliilyticus strains, and one, Vibrio sp. RE88, was found to be the closest outgroup to this species. Strain $V$. mediterranei 71,105 , was the lone pathogen not found within this clade. $V$. coralliilyticus has been previously implicated in disease outbreaks at a West Coast hatchery [11]. Importantly, we did not have a $V$. coralliilyticus strain that did not cause mortalities in tests with $C$. gigas larvae, so although we attempted to control for phylogenetic signal with the phylolm package, we cannot definitively assert that the genes detected with this model are directly related to pathogenesis rather than just being a trait of the species serving some other ecological function. Still, in this discussion we highlight gene features, many of which are conserved in the $V$. coralliilyticus strains we tested, significantly correlated with mortalities, signifying that these genes may set apart pathogens from other vibrios ubiquitous in hatchery and marine environments.

A number of gene clusters negatively correlated with oyster survival were homologous to genes of the CPI-1 pathogenicity island of $V$. coralliilyticus ATCC BAA-450 [33]. Pathogenicity islands are a common way for bacteria to distribute large sets of virulence genes via horizontal gene transfer [34]. The most conspicuous virulence factor encoded by the CPI-1 is a putative T3SS. T3SSs are often used by pathogenic bacteria to invade or manipulate host cells. For example, the T3SS-2 of Vibrio parahaemolyticus facilitates host cell invasion [35]. The observation that the conserved T3SS gene, $s c t V$, is more similar to non-Vibrio T3SS genes is consistent with a previous phylogenetic analysis [36] and suggests that the T3SS, and perhaps the surrounding the CPI-1 island, was acquired through horizontal gene transfer.

It is important to note that, although $V$. pectenicida 99-46-Y appears to encode a relatively complete CPI-1, it was not virulent in our testing. This allows for a comparison of the gene content of the CPI- 1 from pathogens with that of the CPI-1 of $V$. pectenicida 99-46-Y in order to identify those genes that may be specific to oyster larvae pathogenesis. Genes located in CPI-1 of $C$. gigas larvae pathogens, but absent in the non-pathogenic V. pectenicida 99-46-Y, included those annotated as the $v c h A$ hemolysin (AXN30429.1) and another secreted lysin, $v c h B$ (AXN30428.1). These genes are highly similar to two homologs of $V$. vulnificus ( $v v h A[100 \%$ coverage and $76.86 \%$ identity], $v v h B$ [100\% coverage and $59.52 \%$ identity]), which are known to cause epithelial damage and contribute to intestinal growth of the bacterium [37]. Additionally, VchA of V. coralliilyticus, was shown to lyse eukaryotic cells, including erythrocytes [38]. Interestingly, though, culture supernatants from strains of recombinant $V$. cholerae expressing the $v c h A$ gene did not cause significant mortality to C. gigas larvae [18], indicating that although there appears to be a role for this protein in lysing eukaryotic cells, its role as an independent virulence factor in oysters is unclear.

As filter feeding organisms, oysters inherently accumulate large amounts of bacteria from the surrounding water, leading to many coincidental interactions with pathogens. Like other invertebrates, oysters rely on innate immunity and phagocytic cells (e.g., hemocytes in oysters) to protect against pathogenic microbes. Hemocytes are circulatory cells that develop by the early Dveliger larvae stage ( $17 \mathrm{~h}$ post-fertilization) [39] and eliminate bacterial pathogens through specific binding mechanisms, phagocytosis, and subsequent digestion mechanisms [40-43]. Exposure of $C$. gigas larvae to pathogenic $V$. coralliilyticus is known to cause a decline in feeding rate, an activation of the immune response (e.g., hematopoiesis, activation of non-self recognition mechanisms, and production of antimicrobial peptides), and modulation of cell membrane composition [26]. Less is known, though, about the strategies that pathogens employ to escape the immune system of Pacific Oyster. Interestingly, $V$. coralliilyticus RE22 has been shown to suppress immune signalling pathways of Eastern Oyster (Crassostrea virginica) larvae [44]. Our work expands on these findings by identifying additional conserved mechanisms that Vibrio pathogens may utilize to circumvent immune responses by oyster larvae.

For instance, multiple genes of a $\sim 30 \mathrm{~Kb}$-long locus conserved within the genomes of the tested $V$. coralliilyticus isolates and Vibrio sp. strain RE88 were found to be negatively correlated with larvae survival. This locus includes multiple reb genes and their nearby coding sequences, which are predicted to encode "R-bodies". Rbodies are insoluble bacterial proteins that confer a phenotype known as the "killing trait" [45]. R-bodies of the intracellular symbiont, Caedibacter, switch between two stable conformations in response to a stimulus such as an extracellular $\mathrm{pH}$ change that occurs during phagocytosis. R-bodies of Caedibacter cells, which have been internalized within the lysosomes of a symbiont-free competitor paramecium, will then switch into a needle conformation and rupture the bacterial cell wall, whereupon the cytosolic contents will release unidentified toxins that induce paramecium death $[45,46]$. Recombinant Reb proteins from $V$. nigripulchritudo, a shrimp pathogen, have been visualized by transmission electron micrographs [47], and the reb gene cluster of $V$. coralliilyticus are proposed to be derived from a horizontal gene transfer event [48], although no known role has been identified in this species. This region of genes appears to be highly conserved in $V$. coralliilyticus as it is also present in several $V$. coralliilyticus genomes not included in our study (data not shown). The high 
correlation of putative reb genes with pathogenicity make this region a target for further investigation to determine its role in virulence or survival within the host, whereby $V$. coralliilyticus infections may be facilitated by invading and/or modulating the cells of the oyster immune system.

A locus including gene AXN30831.1 was negatively correlated with high rates of larval survival and was annotated to degrade myo-inositol to acetyl-CoA. $V$. coralliilyticus strain BAA-450 is known to utilize myoinositol as a carbon source [20]. Pathogens may be encountering inositol in the host environment. For example, host inositol promotes the growth and virulence of Legionella pneumophila within amoeba and host macrophages [49]. Phosphatidylinositols, membrane lipids with a myo-inositol sugar in the headgroup, have been found to be important in C. gigas growth [50]. Furthermore, there is evidence that both phosphatidylinositol and soluble inositol phosphate signalling plays a role in immune response by bivalve hemocytes $[42,51,52]$, and that C. gigas larvae challenged with Vibrio pathogens show increased in phosphatidyliniositol content [26]. These findings suggest that pathogenic vibrios may modulate oyster immunity by interfering with inositol phosphate signalling, and/or may be able to use host-derived myo-inositol as a carbon and energy source.

Multiple genes annotated to the COG category for carbohydrate utilization were negatively correlated with high larval survival. Two of these were putatively annotated as chitinase genes. One of these is a chiA homolog (AXN33250.1) that is uniquely encoded within $V$. coralliilyticus genomes, and is divergent from another chiA homolog found to be conserved among the genomes of all Vibrio isolates tested. A study by Lin et al. [53] noted that the former homolog was likely introduced into the $V$. coralliilyticus clade via horizontal gene transfer, while the more conserved homolog was hypothesized to be vertically inherited within the genus and under strong purifying selection. Another gene, AXN29974.1, with a partial $N$ - acetylglucosamine-binding protein A domain was also negatively correlated with high larval survival. This domain functions in chitin-binding and in $V$. cholerae [54].

Genes for chitin binding and degradation are present in almost all Vibrio genomes $[53,55]$ and chitin metabolism is an important and highly conserved feature, with roles in survival with marine hosts [56], nutrient acquisition [57], and conjugation of extracellular DNA [58]. With regard to oyster hosts, chitin is one of several essential components of their shell matrix [59], and chitin synthase is highly expressed in early stages of $C$. gigas larval development [60], and in hemocytes and the mantle of adults $[60,61]$. Interestingly, growth of $V$. coralliilyticus strain S2052 on chitin not only induces expression of chitin utilization genes, but also genes related to host colonization, pathogenesis (including rebtype genes), and natural competence [62]. Our observation of a correlation of these putative chitin utilization genes with pathogenicity supports a hypothesis that chitin is a key mediator of interactions between oysters and Vibrio pathogens.

Multiple genes with putative functions for nutrient acquisition were found to be significantly correlated with pathogenicity. Several were proteases, which can aid in colonization of and persistence within a host, degradation of host biomass for energy and carbon acquisition, or the breakdown of accumulated waste [63]. One of these, a S8 serine peptidase (AXN34464.1) was highly similar to a protein ( $97.54 \%$ identity) found in the secretome of a $V$. coralliilyticus $\mathrm{P} 1 \quad v c p A$ mutant that is virulent towards Artemia and Symbiodinium [64]. Additional putative metabolic functions found to correlate negatively (Additional file 6: Table S3) with larval survival included a conserved locus spanning three operons with genes coding for disaccharide transport, as well as the high-affinity pstSCAB phosphate transporter. These metabolism features correlated with pathogenicity may reveal strategies and adaptations for colonization of a host or other environments.

Genes $v c p A, v c p R$, toxR were not found to be significantly associated with pathogenicity, despite being known virulence factors of $V$. coralliilyticus $[18,27,65]$. These genes were generally found to be conserved among all genomes tested here, precluding detection of statistical relationships between their presence/absence and virulence. Additionally, multiple known virulence genes of $V$. splendidus pathogens shown to be important for virulence of species were not significantly correlated with our pathogenicity results, including. Type 6 Secretion Systems (T6SS) [14, 15, 66]. Apparent differences between previous results and ours may arise from minor, but important, differences in sequences of each locus, differences in methods applied for gene clustering, environmental conditions such as temperature, or divergent controls of transcription of conserved genes between pathogenic and non-pathogenic isolates. Host factors such as age (larvae versus adult C. gigas) or a host genotype factor [67] may also account for the divergent results. An additional caveat of our work is that gene clusters detected as in-paralogs, such as one of the T6SS clusters present in many genomes of pathogens, were not analyzed with the phylogenetic logistic regression precluding direct comparisons with previous results.

While only 19 homologous gene clusters were found to be positively correlated with survival of larvae, 508 homologs were identified to negatively correlate with high survival rates, indicating that Vibrio pathogenesis 
towards C. gigas larvae is a complex trait involving multiple adaptive features. The wide diversity of functions encoded by genes correlated with larval pathogenicity, included ones with more classical virulence functions such as proteases and T3SS-related functions, but also genes putatively encoding functions for colonization, nutrient acquisition, and those with unknown functions. Our results indicate that infection of oyster larvae by $V$. coralliilyticus may involve an intracellular stage facilitated by the T3SS and the Reb defense system. We therefore hypothesize that these pathogens interact with the immune system of larvae in a similar manner that is seen for $V$. coralliilyticus infection of the coral Pocillopora damicornis and of $V$. tasmaniensis with oysters, where infection proceeds through the formation of intracellular bacterial aggregates, followed by the repression of host innate immunity, host cell lysis and extensive tissue damage $[15,68,69]$. The genetic features described here will be fruitful targets for future mechanistic studies of the oyster larvae pathogenesis.

\section{Conclusions}

This work highlights the importance of Vibrio genes associated with Pacific oyster (Crassostrea gigas) larvae mortalities. Forty-two newly sequenced hatcheryassociated Vibrio genomes are presented in this study. Out of a wide range of Vibrio species, the most prevalent pathogenic species identified were $V$. coralliilyticus strains. Important considerations of our work are that both pathogenic and non-pathogenic vibrios were isolated from hatcheries when no disease symptoms were evident, and that vibrosis in oysters does not result from one single etiological agent or genetic feature, instead appearing to be a multifaceted trait enabled by many loci. These findings point to the complexity of vibrosis outbreaks, whereby environment, microbial community structure, and genotypic and phenotypic features of Vibrio populations all have important roles in disease outcomes. These findings have meaningful implications on monitoring and management practices of aquaculture, where multiple genetic traits and species are all relevant and must be considered with regard to controlling disease.

\section{Methods}

\section{Pathogenicity of Vibrio isolates against $C$. gigas larvae}

C. gigas larvae were collected $48 \mathrm{~h}$ post-spawn from a hatchery in Newport, Oregon. Seawater was collected from an onsite intake line and autoclaved. Isochrysis $s p$. was used for larvae food. Vibrio isolate strains were grown at a temperature of $25^{\circ} \mathrm{C}$ (with the exception of strain 99-70-13A1, which was grown at $23^{\circ} \mathrm{C}$ ) in $\mathrm{LB}+$ $3 \% \mathrm{NaCl}$ (LBS) to an OD600 of 0.8. Cell cultures were serially diluted in sterile seawater, and cell densities were confirmed by colony forming units (CFUs) on LBS. On the day of larvae collection, larval density was estimated by microscopy. The absence of Vibrio bacteria in unamended stocks of C. gigas larvae and algal feed was confirmed by direct plating on Thiosulfate Citrate Bile Salts Sucrose (TBCS) agar.

Challenges with Vibrio isolate strains and C. gigas larvae were performed in sterile 24-well plates. For each replicate challenge, 20-30 larvae and $10^{5}$ Vibrio cells $/ \mathrm{ml}$ in sterile seawater were added to each well at a final volume of $6 \mathrm{ml}$. Bacteria-free controls were performed with larvae alone in sterile seawater. Known pathogenic ( $V$. coralliilyticus str. RE98) and non-pathogenic ( $V$. cyclitrophicus HMSC5) isolates, added at d $10^{5}$ Vibrio cells $/ \mathrm{ml}$ in sterile seawater, were used in challenges as positive and negative controls, respectively. Wells were sealed with parafilm and covered during subsequent incubations at $25^{\circ} \mathrm{C}$ for $48 \mathrm{~h}$. The neutral red uptake assay was performed post-challenge to quantify larvae mortality. Briefly, neutral red solution was added to each well at a final concentration of $0.0002 \%(\mathrm{v} / \mathrm{v})$. After $3 \mathrm{~h}, 30 \mu \mathrm{l}$ of $10 \%$ buffered formalin was added to wells. Larvae were visualized with a dissecting microscope to characterize morphology and quantify dye uptake. Each Vibrio isolate was tested in quadruplicate, and mean mortality rates and standard deviations are reported. Each strain was tested for hemolytic and proteolytic activity. To test for extracellular proteolytic activity, strains were streaked on LB supplemented with $\mathrm{NaCl}$ (3\%) and skim milk (2\%) agar and incubated at room temperature $\left(\sim 21^{\circ} \mathrm{C}\right)$ and $28^{\circ} \mathrm{C}$ for $48 \mathrm{~h}$. To test for hemolytic activity, strains were streaked on Nutrient Agar supplemented with horse blood (5\%) at room temperature for $48 \mathrm{~h}$.

\section{Genome sequencing and assembly}

All Vibrio strains were obtained from culture collections or isolated directly from samples collected from commercial shellfish hatcheries. Isolates from hatcheries were obtained by plating samples of intake water and larvae tanks on TCBS. Colonies characteristic of Vibrio spp. were restreaked for isolation before growth in liquid broth and cryogenic preservation at $-80^{\circ} \mathrm{C}$.

Genomic DNA from overnight cultures of isolates was purified using the phenol-chloroform extraction method [70] or a DNeasy Blood \& Tissue Kits (QIAGEN, Venlo, Netherlands). Quality and quantity of isolated genomic DNA was assessed by electrophoresis on a $0.9 \%$ agarose gel, by measuring absorbance wavelengths at 260 and 280 $\mathrm{nm}$, and Qubit fluorometry (Thermo Fisher Scientific, Waltham, MA USA). DNA sequencing libraries of genomic DNAs were prepared using Nextera XT kit (Illumina Inc., San Diego, CA USA). Libraries were pooled together at equal concentrations and sequenced using the Illumina 
Miseq Platform $(2 \times 250 \mathrm{bp})$ at Oregon State University's Center for Genome Research and Biocomputing (CGRB). Raw sequencing reads were demultiplexed and barcodes removed prior to quality-filtering and trimming using Sickle. High quality reads were then randomly subsampled to obtain approximately 50-fold coverage of the genome and assembled using IDBA-UD version 1.0.6 [71] with iterative k-mer assembly between a 45 and 105 with 4-mer increments. Annotation of contigs $>500 \mathrm{bp}$ was conducted with Prokka with default settings [72]. Completeness and purity of assembled genomes was assessed with the CheckM tool [73]. Average-nucleotide identity (ANI) values between all sequenced genomes and a downloaded set of reference genomes from all Vibrio species available from NCBI Genbank (date accessed: May 1st 2018) were calculated using the tool FastANI [74]. A 95\% ANI cut-off ratio to reference genomes was used to putatively assign species labels to each of the newly sequenced genomes [74-76].

\section{Comparative genomics and phylogenomics}

Homologous clusters of gene families were identified using the GET_HOMOLOGUES software package [77] with OrthoMCL clustering [32] using default parameters. Orthologous clusters containing two or more members from the same genome (defined as inparalogs) were excluded $(n=1087)$ from subsequent statistical tests. The "core genome" was defined as those genes present in all 51 strains tested, while the "soft core genome" was defined as genes found in greater than 95\% of the 51 genomes analyzed. The "flex genome" was defined as those genes present in 5-95\% of the genomes. The Heaps law model [78] was used with the function "heaps" in the R package micropan [79] to estimate pan genome openness.

A phylogeny based on single-copy universal genes was built for the 51 tested Vibrio genomes using the "bcgTree" pipeline [80]. Briefly, the hmmer program (version 3.1b2, http://hmmer.org/) searched all predicted protein coding sequences from the Vibrio genomes against a database of hidden markov model (hmm) profiles of genes present in over $95 \%$ of bacterial genomes [81]. Best matches above a gene-specific cut-off were retained and query sequences with the same database match were aligned using MUSCLE with default settings [82]. Resulting alignments were filtered with Gblocks [83] and concatenated with AMAS [84]. RAxML was used to build a partitioned maximum likelihood phylogenetic tree from this alignment, using a GAMMA distribution of rate heterogeneity and individually estimated models of evolution for each gene partition of the concatenated alignment [85].

A phylogeny was constructed from the core genome of all newly sequenced Vibrio genomes, 98 reference Vibrio genomes, and the Enterovibrio norvegicus DSM 15893 and Photobacterium gaetbulicola Gung47 genomes as outgroups. All reference genomes downloaded as nucleotide fastas from RefSeq and annotated using the PROKKA pipeline for consistency. Genomes with an N90 under 10,000 bp, estimated to be less than $90 \%$ complete, or with high strain heterogeneity were excluded from further analysis. To define the core genome of this dataset amino acid sequences from all genes were used as input for the GET_HOMOLOGUES pipeline. OrthoMCL was used to cluster protein sequences with $50 \%$ minimum coverage, $50 \%$ minimum identity and a default e-value of 0.00001 . A concatenated alignment and phylogenomic tree was then created from the core set of homologous genes as described above for the single copy, universal gene data set. The two phylogenies were then analyzed for congruency with one another using the 'treedist' function in the package 'phangorn' [86] with KF distance.

\section{Detection of gene orthologs correlated with pathogenicity}

To identify the set of genes in Vibrio genomes significantly associated with larvae mortalities, correlations between presence or absence of genes and the results of larval pathogenicity assays were calculated with a phylogenetic logistic regression model of the R package "phylolm" (86). Gene presence/absence across all genomes was considered binary response variable and percent survival was considered a predictor variable for each model, and all single-copy genes present in 3 or more genomes but not more than 46 genomes $(n=6676)$ were tested. The phylogeny constructed from single-copy, universal genes was used as input for the model. Gene occurrences were considered significantly correlated with larvae data using a $p$-value cutoff of 0.005 , and the effect of the relationship was determined by the strength and sign of the correlation estimate.

\section{Functional category analysis}

Orthologous gene clusters were functionally annotated against the Non-supervised Orthologous Groups database (eggNOG) [87]. Each orthologous cluster was aligned with MUSCLE [82], and an hmm profile was built HMMER, which was then used to search against the eggNOG GAMMAPROTNOG database to provide a consistent annotation of each respective cluster. A chisquared test was conducted to compare the distribution of functional categories for genes identified to be significantly negatively correlated with larvae survival to the distribution of functional categories for genes in the core genome. Pairwise post-hoc tests for each functional category were then performed with an FDR correction to determine which individual functional categories were 
significantly different between each dataset. Categories were considered enriched at a significance level of $p<$ 0.05 .

\section{Phylogeny of T3SS genes}

To infer phylogenetic relationships of specific genes, including the sctN (the Type III secretion cytoplasmic ATPase) and sctV (Type III secretion inner membrane protein) homologues, hmm profiles for genes of interest were obtained from the Pfam database [88]. These profiles were used to search against a database of putative protein sequences from the newly sequenced and reference Vibrio genomes. Best matches falling within an inclusion threshold of an E-value $\leq 0.01$ were selected as putative homologues for downstream analyses. A multiple sequence alignment with identified homologues, as well as a database of reference proteins for sequences of interest, was created with MUSCLE [82]. A maximum-likelihood phylogenetic tree was constructed using RAxML with GAMMA model of rate heterogeneity and the LG model of protein substitution and empirical base frequencies (as determined by automated protein model assignment).

\section{Supplementary information}

Supplementary information accompanies this paper at https://doi.org/10. 1186/s12864-020-06980-6.

Additional file $\mathbf{1}$ Table $\mathbf{S 1}$. Hemolysis and proteolysis reactions. Additional file 2 Fig. S1. Heatmap and dendrogram of Average Nucleotide Identity (ANI) calculations between pairs of different Vibrio strains, including strains used in this study and reference strains. ANI of $\geq 95 \%$ with a Type Strain of a species was used for species designation of newly sequenced strains. Strains without ANI $\geq 95 \%$ with any Type Strain were designated "sp."

Additional file 3 Fig. S2. Phylogenetic Tree of strains used in this study and reference strains. A concatenated alignment of 686 conserved amino acid sequences from single copy orthologous genes was used to construct a maximum likelyhood phylogeny.

Additional file 4 Fig. S3. Core and Pan-genome of 51 isolates in this study. (A) the core-genome represents all genes shared by each genome added. (B) The pan-genome represents the accumulation of all genes among all genomes with the addition of each genome.

Additional file $\mathbf{5}$ Table S2. Phylogenetic logistic regression results.

Additional file $\mathbf{6}$ Table S3. Metabolism and nutrient acquisition genes significantly correlated with larvae survival/mortality.

Additional file 7 Fig. S4. Count distributions of bactNOG functional categories of genes among categories of different gene sets. The "Core in All" column refers to the core genome ( $n=1693$ gene clusters) of all strains $(n=51)$. The "Core in Non-Pathogens" column refers to the core genome ( $n=1775$ gene clusters) of all strains $(n=34)$ that are nonpathogenic ( 0.5 or lower mortality ratio). The "Core in Pathogens" column refers to the core genome ( $n=2646$ gene clusters) of pathogenic strains. The "Exclusive to Non-Pathogens" column refers to genes ( $n=4010$ gene clusters) that are found only in non-pathogens, but not necessarily conserved. The "Exclusive to Pathogens" column refers to genes ( $n=1981$ gene clusters) that are found only in pathogens, but not necessarily conserved. The "Flexible" column refers to genes ( $n=3345$ gene clusters) that are found at least once in both pathogens and non-pathogens, but are not conserved in either. The "Phyloglm Significant with Mortalities" column refers to all genes ( $n=509$ gene clusters) that had a significant correlation with pathogenicity towards $\mathrm{C}$. gigas larvae.

Additional file 8 Fig. S5. Gene organization of the CPI-1 region within the complete genome of $V$. corallilyticus RE22 and the draft genome of $V$. pectenicida 99-46-Y. Pink arrows indicate that the gene had a negative correlation with larval survival in virulence assays. Blue arrows indicate that there was no significant correlation with survival or that the gene was not tested. Yellow slashed lines indicate contig breaks on the CPI-1 of the $V$. pectenicida strain 99-46-Y draft genome.

Additional file $\mathbf{9}$ Fig. S6. Predicted phylogeny of Type 3 Secretion Systems using SctV amino acid sequences. Clades are color coded. Included in the phylogeny are proteins from tested isolates, specific Vibrio reference genomes, and from COG4789 comprised of more diverse reference genomes. Scale bar represents one change per amino acid. Tree was visualized with iTOL.

Additional file $\mathbf{1 0}$ Table S4. Pan-genome table (excluding genes only found once in a genome) with strain RE22 for reference loci.

\section{Abbreviations}

ANI: Average nucleotide identity; eggNOG: Non-supervised orthologous groups database; COG: Clusters of orthologous groups; CPI-1: Coralliilyticus pathogenicity island 1; KF: Kuhner-felsenstein; MARTX: Multifunctionalautoprocessing repeats-in-toxin; RTX: Repeats-in-toxin; T1SS: Type 1 secretion system; T3SS: Type 3 secretion system; T6SS: Type 6 secretion system

\section{Acknowledgements}

We thank Ralph Elston and Gary Richards for providing several isolates used in this study, Blake Ushijima and Carla Schubiger for technical assistance, and David Madison for providing oyster larvae and advice in virulence assays.

\section{Authors' contributions}

HD performed wet-lab experiments, analysed the data, and drafted the manuscript. RSM and $\mathrm{CH}$ supervised the study and revised the manuscript. All authors read and approved the final manuscript.

\section{Funding}

This work was supported by Special Research Grants Program - Aquaculture Research, grant number: 2015-70007-24240 / project accession no. 1007649) from the USDA National Institute of Food and Agriculture. HD was a recipient of the OSU Tartar Fellowship and John Fryer Scholarship. The funding bodies were not involved in design of the study and collection, analysis, and interpretation of results or in writing the manuscript.

\section{Availability of data and materials}

The draft genomes of the 42 Vibrio isolates have been deposited in the GenBank database under project accession no. PRJNA563078.

Ethics approval and consent to participate

Not applicable.

\section{Consent for publication}

Not applicable.

\section{Competing interests}

The authors declare that they have no competing interests.

\section{Author details}

${ }^{1}$ Department of Microbiology, Oregon State University, Corvallis, Oregon 97331, USA. ${ }^{2}$ Carlson College of Veterinary Medicine, Oregon State University, Corvallis, Oregon, USA.

Received: 18 March 2020 Accepted: 11 August 2020

Published online: 31 August 2020

\section{References}

1. Nair GB. Seasonal distribution of Vibrio parahaemolyticus in freshwater environs and in association with freshwater fishes in Calcutta. Appl Env Microbiol. 1985;49:5. 
2. Thompson JR, Randa MA, Marcelino LA, Tomita-Mitchell A, Lim E, Polz MF Diversity and dynamics of a North Atlantic coastal Vibrio community. Appl Environ Microbiol. 2004;70:4103-10.

3. Gradoville MR, Crump BC, Häse CC, White AE. Environmental controls of oyster-pathogenic Vibrio spp. in Oregon estuaries and a shellfish hatchery. Appl Environ Microbiol. 2018;84. https://doi.org/10.1128/AEM.02156-17.

4. Beaz Hidalgo R, Cleenwerck I, Balboa S, Prado S, De Vos P, Romalde JL. Vibrio breoganii sp. nov., a non-motile, alginolytic, marine bacterium within the Vibrio halioticoli clade. Int J Syst Evol Microbiol. 2009;59: 1589-94.

5. Chonsin K, Matsuda S, Theethakaew C, Kodama T, Junjhon J, Suzuki Y, et al. Genetic diversity of Vibrio parahaemolyticus strains isolated from farmed Pacific white shrimp and ambient pond water affected by acute hepatopancreatic necrosis disease outbreak in Thailand. FEMS Microbiol Lett. 2016;363:fnv222.

6. Alam M, Sultana M, Nair GB, Siddique AK, Hasan NA, Sack RB, et al. Viable but nonculturable Vibrio cholerae $\mathrm{O} 1$ in biofilms in the aquatic environment and their role in cholera transmission. Proc Natl Acad Sci. 2007;104:17801-6.

7. Yawata Y, Cordero OX, Menolascina F, Hehemann J-H, Polz MF, Stocker R. Competition-dispersal tradeoff ecologically differentiates recently speciated marine bacterioplankton populations. Proc Natl Acad Sci. 2014;111:5622-7.

8. Toranzo AE, Magariños B, Romalde $J$. A review of the main bacterial fish diseases in mariculture systems. Aquaculture. 2005;246:37-61.

9. Elston R, Leibovitz L, Relyea D, Zatila J. Diagnosis of vibriosis in a commercial oyster hatchery epizootic: diagnostic tools and management features. Aquaculture. 1981;24:53-62.

10. Prado S, Romalde J, Montes J, Barja J. Pathogenic bacteria isolated from disease outbreaks in shellfish hatcheries. First description of Vibrio neptunius as an oyster pathogen. Dis Aquat Org. 2005;67:209-15.

11. Elston R, Hasegawa H, Humphrey K, Polyak I, Häse C. Re-emergence of Vibrio tubiashii in bivalve shellfish aquaculture: severity, environmental drivers, geographic extent and management. Dis Aquat Org. 2008:82:119-34.

12. Prado S, Dubert J, Barja JL. Characterization of pathogenic vibrios isolated from bivalve hatcheries in Galicia, NW Atlantic coast of Spain. Description of Vibrio tubiashii subsp. europaensis subsp. nov. Syst Appl Microbiol. 2015;38:26-9.

13. Bruto M, James A, Petton B, Labreuche $Y$, Chenivesse $S$, Alunno-Bruscia M, et al. Vibrio crassostreae, a benign oyster colonizer turned into a pathogen after plasmid acquisition. ISME J. 2017;11:1043-52.

14. Bruto M, Labreuche $Y$, James A, Piel D, Chenivesse S, Petton B, et al. Ancestral gene acquisition as the key to virulence potential in environmental Vibrio populations. ISME J. 2018;12:2954-66

15. Rubio T, Oyanedel D, Labreuche $Y$, Toulza E, Luo X, Bruto M, et al. Species-specific mechanisms of cytotoxicity toward immune cells determine the successful outcome of Vibrio infections. Proc Natl Acad Sci. 2019:116:14238-47.

16. Binesse J, Delsert C, Saulnier D, Champomier-Verges M-C, Zagorec M,

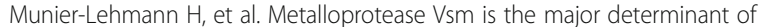
toxicity for extracellular products of Vibrio splendidus. Appl Environ Microbiol. 2008;74:7108-17.

17. Labreuche Y, Le Roux F, Henry J, Zatylny C, Huvet A, Lambert C, et al. Vibrio aestuarianus zinc metalloprotease causes lethality in the Pacific oyster Crassostrea gigas and impairs the host cellular immune defenses. Fish Shellfish Immunol. 2010;29:753-8.

18. Hasegawa H, Lind EJ, Boin MA, Hase CC. The extracellular Metalloprotease of Vibrio tubiashii is a major virulence factor for Pacific oyster (Crassostrea gigas) larvae. Appl Environ Microbiol. 2008;74:4101-10.

19. Ben-Haim Y, Rosenberg E. A novel Vibrio sp. pathogen of the coral Pocillopora damicornis. Mar Biol. 2002;141:47-55.

20. Ben-Haim Y. Vibrio coralliilyticus sp. nov., a temperature-dependent pathogen of the coral Pocillopora damicornis. Int J Syst Evol Microbiol. 2003;53:309-15.

21. Ushijima B, Videau $P$, Burger AH, Shore-Maggio A, Runyon CM, Sudek M, et al. Vibrio coralliilyticus strain OCN008 is an etiological agent of acute Montipora White syndrome. Appl Environ Microbiol. 2014;80:2102-9.

22. Tubiash HS, Chanley PE, Leifson E. Bacillary necrosis, a disease of larval and juvenile bivalve mollusks. J Bacteriol. 1965;90:9.

23. Estes R, Friedman C, Elston R, Herwig R. Pathogenicity testing of shellfish hatchery bacterial isolates on Pacific oyster Crassostrea gigas larvae. Dis Aquat Org. 2004;58:223-30.
24. Gómez-León J, Villamil L, Salger S, Sallum R, Remacha-Triviño A, Leavitt D, et al. Survival of eastern oysters Crassostrea virginica from three lines following experimental challenge with bacterial pathogens. Dis Aquat Org. 2008;79:95-105.

25. Richards GP, Watson MA, Needleman DS, Church KM, Häse CC. Mortalities of eastern and Pacific oyster larvae caused by the pathogens Vibrio coralliilyticus and Vibrio tubiashii. Appl Environ Microbiol. 2015;81:292-7.

26. Genard B, Miner P, Nicolas J-L, Moraga D, Boudry P, Pernet F, et al. Integrative study of physiological changes associated with bacterial infection in Pacific oyster larvae. PLoS One. 2013;8:e64534.

27. Ushijima B, Richards GP, Watson MA, Schubiger CB, Häse CC. Factors affecting infection of corals and larval oysters by Vibrio coralliilyticus. PLoS One. 2018;13:e0199475.

28. Kehlet-Delgado H, Richards GP, Häse C, Mueller RS. Three draft genome sequences of Vibrio coralliilyticus strains isolated from bivalve hatcheries. Genome Announc. 2017;5:e01162-17.

29. Ushijima B, Videau P, Poscablo D, Stengel JW, Beurmann S, Burger AH, et al. Mutation of the toxR or mshA genes from Vibrio coralliilyticus strain OCN014 reduces infection of the coral Acropora cytherea: virulence genes in Vibrio coralliilyticus. Environ Microbiol. 2016;18:4055-67.

30. Gharaibeh DN, Hasegawa H, Häse CC. Development of a quantitative realtime PCR assay for detection of Vibrio tubiashii targeting the metalloprotease gene. J Microbiol Methods. 2009;76:262-8.

31. Kuhner M, Felsenstein J. A simulation comparison of phylogeny algorithms under equal and unequal evolutionary rates. Mol Biol Evol. 1994. https://doi. org/10.1093/oxfordjournals.molbev.a040126.

32. Li L. OrthoMCL: identification of Ortholog groups for eukaryotic genomes. Genome Res. 2003;13:2178-89.

33. Kimes NE, Grim CJ, Johnson WR, Hasan NA, Tall BD, Kothary MH, et al. Temperature regulation of virulence factors in the pathogen Vibrio coralliilyticus. ISME J. 2012;6:835-46.

34. Dobrindt U, Hochhut B, Hentschel U, Hacker J. Genomic islands in pathogenic and environmental microorganisms. Nat Rev Microbiol. 2004;2: 414-24.

35. Zhang L, Krachler AM, Broberg CA, Li Y, Mirzaei H, Gilpin CJ, et al. Type III effector VopC mediates invasion for Vibrio species. Cell Rep. 2012;1:453-60.

36. Hu Y, Huang H, Cheng X, Shu X, White AP, Stavrinides J, et al. A global survey of bacterial type III secretion systems and their effectors: a global survey of bacterial type III secretion systems. Environ Microbiol. 2017;19: 3879-95.

37. Jeong H-G, Satchell KJF. Additive function of Vibrio vulnificus MARTXVV and VvhA Cytolysins promotes rapid growth and epithelial tissue necrosis during intestinal infection. PLoS Pathog. 2012;8:e1002581.

38. Kothary MH, Delston RB, Curtis SK, McCardell BA, Tall BD. Purification and characterization of a Vulnificolysin-like Cytolysin produced by Vibrio tubiashii. Appl Environ Microbiol. 2001;67:3707-11.

39. Song $X$, Wang $H$, Xin $L, X u J$, Jia Z, Wang $L$, et al. The immunological capacity in the larvae of Pacific oyster Crassostrea gigas. Fish Shellfish Immunol. 2016:49:461-9.

40. Allam B, Paillard C. Defense factors in clam extrapallial fluids. Dis Aquat Org. 1998:33:123-8.

41. Allam B, Pales EE. Bivalve immunity and response to infections: are we looking at the right place? Fish Shellfish Immunol. 2016;53:4-12.

42. Canesi L, Scarpato A, Betti M, Ciacci C, Pruzzo C, Gallo G. Bacterial killing by mytilus hemocyte monolayers as a model for investigating the signaling pathways involved in mussel immune defence. Mar Environ Res. 2002;54: 547-51.

43. Schmitt $P$, Rosa RD, Duperthuy $M$, de Lorgeril J, Bachère $E$, DestoumieuxGarzón D. The antimicrobial defense of the pacific oyster, crassostrea gigas. How diversity may compensate for scarcity in the regulation of resident/ pathogenic microflora. Front Microbiol. 2012;3. https://doi.org/10.3389/ fmicb.2012.00160

44. Modak T. Eastern oyster larval Transcriptomes in response to probiotic and pathogenic Bacteria. PhD Thesis. University of Rhode Island; 2018.

45. Pond FR, Gibson I, Lalucat J, Quackenbush RL. R-body-producing bacteria. Microbiol Mol Biol Rev. 1989:53:25-67.

46. Polka JK, Silver PA. A tunable protein piston that breaks membranes to release encapsulated cargo. ACS Synth Biol. 2016;5:303-11.

47. Goudenège $D$, Labreuche $Y$, Krin E, Ansquer D, Mangenot S, Calteau A, et al. Comparative genomics of pathogenic lineages of Vibrio nigripulchritudo identifies virulence-associated traits. ISME J. 2013;7:1985-96. 
48. Raymann K, Bobay L-M, Doak TG, Lynch M, Gribaldo S. A genomic survey of reb homologs suggests widespread occurrence of R-bodies in proteobacteria. G3amp58 GenesGenomesGenetics. 2013;3:505-16.

49. Manske C, Schell U, Hilbi H. Metabolism of myo -inositol by legionella pneumophila promotes infection of amoebae and macrophages. Appl Environ Microbiol. 2016;82:5000-14.

50. Zhang F, Hu B, Fu H, Jiao Z, Li Q, Liu S. Comparative Transcriptome analysis reveals molecular basis underlying fast growth of the selectively bred Pacific oyster, Crassostrea gigas. Front Genet. 2019;10:610.

51. Malagoli D, Franchini A, Ottaviani E. Synergistic role of CAMP and IP3 in corticotropin-releasing hormone-induced cell shape changes in invertebrate immunocytes. Peptides. 2000;21:175-82.

52. Wang Z, Wang B, Chen G, Jian J, Lu Y, Xu Y, et al. Transcriptome analysis of the pearl oyster ( Pinctada fucata) hemocytes in response to Vibrio alginolyticus infection. Gene. 2016;575:421-8.

53. Lin $H$, Yu M, Wang $X$, Zhang $X-H$. Comparative genomic analysis reveals the evolution and environmental adaptation strategies of vibrios. BMC Genomics. 2018;19. https://doi.org/10.1186/s12864-018-4531-2.

54. Kirn TJ, Jude BA, Taylor RK. A colonization factor links Vibrio cholerae environmental survival and human infection. Nature. 2005;438:863-6.

55. Hunt DE, Gevers D, Vahora NM, Polz MF. Conservation of the chitin utilization pathway in the Vibrionaceae. Appl Environ Microbiol. 2008;74:44-51.

56. Mondal M, Nag D, Koley H, Saha DR, Chatterjee NS. The Vibrio cholerae extracellular Chitinase ChiA2 is important for survival and pathogenesis in the host intestine. PLoS One. 2014;9:e103119.

57. Svitil AL. Chitin degradation proteins produced by the marine bacterium Vibrio harveyi growing on different forms of chitin. Appl Env Microbiol. 1997;63:6.

58. Meibom KL. Chitin induces natural competence in Vibrio cholerae. Science 2005:310:1824-7.

59. Suzuki M, Sakuda S, Nagasawa H. Identification of chitin in the prismatic layer of the Shell and a chitin synthase gene from the Japanese pearl oyster, Pinctada fucata. Biosci Biotechnol Biochem. 2007;71:1735-44.

60. Zhang G, Fang X, Guo X, Li L, Luo R, Xu F, et al. The oyster genome reveals stress adaptation and complexity of shell formation. Nature. 2012;490:49-54.

61. Ivanina AV, Falfushynska HI, Beniash E, Piontkivska H, Sokolova IM. Biomineralization-related specialization of hemocytes and mantle tissues of the Pacific oyster Crassostrea gigas. J Exp Biol. 2017;220:3209-21.

62. Giubergia S, Phippen C, Nielsen KF, Gram L. Growth on chitin impacts the transcriptome and metabolite profiles of antibiotic-producing Vibrio coralliilyticus S2052 and Photobacterium galatheae S2753. mSystems. 2017;2: e00141-16/msys/2/1/e00141-16.atom.

63. Johnson CN. Fitness factors in Vibrios: a mini-review. Microb Ecol. 2013;65: 826-51.

64. de O Santos E, Alves N, Dias GM, Mazotto AM, Vermelho A, Vora GJ, et al. Genomic and proteomic analyses of the coral pathogen Vibrio coralliilyticus reveal a diverse virulence repertoire. ISME J. 2011;5:1471-83.

65. Hasegawa $H$, Hase CC. TetR-type transcriptional regulator $V t p R$ functions as a global regulator in Vibrio tubiashii. Appl Environ Microbiol. 2009;75:7602-9.

66. Piel D, Bruto M, James A, Labreuche $Y$, Lambert C, Janicot A, et al. Selection of Vibrio crassostreae relies on a plasmid expressing a type 6 secretion system cytotoxic for host immune cells. Environ Microbiol. 2019. https://doi. org/10.1111/1462-2920.14776.

67. Wendling CC, Wegner KM. Adaptation to enemy shifts: rapid resistance evolution to local Vibrio spp. in invasive Pacific oysters. Proc R Soc B Biol Sci. 2015;282:20142244

68. Vidal-Dupiol J, Ladriere O, Meistertzheim A-L, Foure L, Adjeroud M, Mitta G. Physiological responses of the scleractinian coral Pocillopora damicornis to bacterial stress from Vibrio coralliilyticus. J Exp Biol. 2011;214:1533-45.

69. Vidal-Dupiol J, Dheilly NM, Rondon R, Grunau C, Cosseau C, Smith KM, et al. Thermal stress triggers broad Pocillopora damicornis Transcriptomic remodeling, while Vibrio coralliilyticus infection induces a more targeted Immuno-suppression response. PLoS One. 2014;9:e107672.

70. Crump BC, Kling GW, Bahr M, Hobbie JE. Bacterioplankton community shifts in an Arctic Lake correlate with seasonal changes in organic matter source. Appl Environ Microbiol. 2003;69:2253-68.

71. Peng Y, Leung HCM, Yiu SM, Chin FYL. IDBA-UD: a de novo assembler for single-cell and metagenomic sequencing data with highly uneven depth. Bioinformatics. 2012;28:1420-8.

72. Seemann T. Prokka: rapid prokaryotic genome annotation. Bioinformatics. 2014;30:2068-9
73. Parks DH, Imelfort M, Skennerton CT, Hugenholtz P, Tyson GW. CheckM: assessing the quality of microbial genomes recovered from isolates, single cells, and metagenomes. Genome Res. 2015;25:1043-55.

74. Jain C, Rodriguez-R LM, Phillippy AM, Konstantinidis KT, Aluru S. High throughput ANI analysis of 90K prokaryotic genomes reveals clear species boundaries. Nat Commun. 2018;9. https://doi.org/10.1038/s41467-01807641-9.

75. Konstantinidis KT, Tiedje JM. Genomic insights that advance the species definition for prokaryotes. Proc Natl Acad Sci. 2005;102:2567-72.

76. Goris J, Konstantinidis KT, Klappenbach JA, Vandamme P, Coenye T, Tiedje JM. DNA-DNA hybridization values and their relationship to whole-genome sequence similarities. Int J Syst Evol Microbiol. 2007;57:81-91.

77. Contreras-Moreira B, Vinuesa P. GET_HOMOLOGUES, a versatile software package for scalable and robust microbial Pangenome analysis. Appl Environ Microbiol. 2013;79:7696-701.

78. Tettelin H, Riley D, Cattuto C, Medini D. Comparative genomics: the bacterial pan-genome. Curr Opin Microbiol. 2008;11:472-7.

79. Snipen L, Liland KH. micropan: an R-package for microbial pan-genomics. BMC Bioinformatics. 2015;16. https://doi.org/10.1186/s12859-015-0517-0.

80. Ankenbrand MJ, Keller A. bcgTree: automatized phylogenetic tree building from bacterial core genomes. Genome. 2016;59:783-91.

81. Dupont CL, Rusch DB, Yooseph S, Lombardo M-J, Alexander Richter R, Valas $R$, et al. Genomic insights to SAR86, an abundant and uncultivated marine bacterial lineage. ISME J. 2012;6:1186-99.

82. Edgar RC. MUSCLE: multiple sequence alignment with high accuracy and high throughput. Nucleic Acids Res. 2004;32:1792-7.

83. Castresana J. Selection of conserved blocks from multiple alignments for their use in phylogenetic analysis. Mol Biol Evol. 2000;17:540-52.

84. Borowiec ML. AMAS: a fast tool for alignment manipulation and computing of summary statistics. PeerJ. 2016;4:e1660.

85. Liu K, Linder CR, Warnow T. RAxML and FastTree: comparing two methods for large-scale maximum likelihood phylogeny estimation. PLoS One. 2011;6: e27731.

86. Schliep KP. Phangorn: phylogenetic analysis in R. Bioinformatics. 2011;27: 592-3.

87. Powell S, Szklarczyk D, Trachana K, Roth A, Kuhn M, Muller J, et al. eggNOG v3.0: orthologous groups covering 1133 organisms at 41 different taxonomic ranges. Nucleic Acids Res. 2012;40:D284-9.

88. El-Gebali S, Mistry J, Bateman A, Eddy SR, Luciani A, Potter SC, et al. The Pfam protein families database in 2019. Nucleic Acids Res. 2019;47:D427-32.

\section{Publisher's Note}

Springer Nature remains neutral with regard to jurisdictional claims in published maps and institutional affiliations.

Ready to submit your research? Choose BMC and benefit from:

- fast, convenient online submission

- thorough peer review by experienced researchers in your field

- rapid publication on acceptance

- support for research data, including large and complex data types

- gold Open Access which fosters wider collaboration and increased citations

- maximum visibility for your research: over $100 \mathrm{M}$ website views per year

At BMC, research is always in progress.

Learn more biomedcentral.com/submissions 